Bioscientia Medicina: Journal of Biomedicine \& Translational Research

Journal Homepage: www.bioscmed.com

\title{
Bronchiectasis with Multiple Bullae Post-Extraction Corpus Alineum Comorbid with Pulmonary Tuberculosis
}

\section{Dewi Wahyu Fitrina ${ }^{*}$, Yulia Helexandra ${ }^{1}$}

${ }^{1}$ Department of Pulmonology and Respiration Medicine, Faculty of Medicine, Universitas Andalas/ Dr. M. Djamil General Hospital, Padang, Indonesia

\author{
A R T I C L E I N F O \\ Keywords: \\ Bronchiectasis \\ Pulmonary tuberculosis \\ Bullae \\ Corpus alineum \\ Aspiration \\ *Corresponding author: \\ Dewi Wahyu Fitrina \\ E-mail address:

\section{fitrinadewi815@gmail.com}

All authors have reviewed and approved the final version of the manuscript.

https://doi.org/10.37275/bsm.v6i3.468

\begin{abstract}
A B S T R A C T
Background. Bronchiectasis is a chronic inflammatory airway disease characterized by chronic bronchial dilatation. The cause of bronchiectasis is still ideopathic but most of the bronchiectasis are caused by tuberculosis infection and will interfere with the patient's quality of life. In addition, bronchiectasis can be caused by aspiration of foreign bodies. Case presentation: A 42-year-old male patient was treated at Dr, M Djamil Padang Hospital with complaints of coughing up blood, in addition the patient complained of coughing up yellowish phlegm, shortness of breath and fever. The patient had a history of foreign body aspiration 6 months ago. The patient had a chest X-ray and a chest CT scan and a picture of bronchiectasis and mulltiple bullae was found. The patient also had pulmonary tuberculosis infection where the X-pert gene examination in the patient found that MTB was not detected. Conclusion: The patient had multiple bullae, which were complications of emphysema, and the patient had or had compensatory emphysema, where the abnormality was hyperinflation of certain parts of the lung due to atelectasis. The condition of bronchiectasis and multiple bullae makes the patient susceptible to infection, which in this case was found to have pulmonary tuberculosis infection. Management of bronchiectasis includes identification of acute exacerbations and the use of antibiotics, controlling microbial growth, treatment of the underlying condition, and reducing the excessive inflammatory response.
\end{abstract}

\section{Introduction}

Bronchiectasis is a chronic inflammatory airway disease characterized by clinical symptoms of chronic cough, increased sputum production, and bronchial infection, as well as abnormal radiological features characterized by permanent dilation or dilation of the bronchi. Primary clinical manifestations of primary bronchiectasis are recurrent, chronic, or refractory infections with symptoms that occur are coughing up blood, airway, and progressive breathing problems. In the United States, from 2000 to 2007 the prevalence of bronchiectasis was reported to have increased. Seitz et al reported that the prevalence of bronchiectasis increased by $8.74 \%$ every year and occurred at the age of 80-84 years. The prevalence of bronchiectasis is more common in women and Asian races. Decreased FEV1 rates, advanced dyspnoea symptom scores, positive Pseudomonas culture results, low basal metabolic index, male, advanced age, and COPD have been identified as risk factors for mortality. 1,2,3,4,5

Causes of bronchiectasis $50-80 \%$ are still idiopathic, a British study in 2000 on 150 patients found $53 \%$ idiopathic causes. Bronchiectasis is mostly caused by tuberculosis and will interfere with the patient's quality of life. According to the report on the 
control of pulmonary TB (tuberculosis) issued by the WHO in 2012, Indonesia is the fourth largest country in the world that has TB sufferers after India, China, and South Africa. Gothi et al in 2007 found out of 268 patients in tertiary health centers in India, $13 \%$ of them had bronchiectasis, and $78 \%$ of them were posttuberculosis patients. In addition, bronchiectasis can be caused by the aspiration of foreign bodies. $5,7,15$

\section{Case Presentation}

A 42-year-old male patient came to the Emergency Unit (IGD) Dr. M Djamil Padang with complaints of coughing up blood since 1 day ago, fresh red blood with the amount of blood coming out of $600 \mathrm{cc}$ in 2 hours. The patient also complained of increased coughing since 1 week ago, coughing up yellowish phlegm, and the cough has been felt since 1 month ago, white phlegm, more sputum is expelled in the morning. The patient complained of shortness of breath for 1 day, shortness of breath did not shrink and increased with coughing. Complaints of fever since 3 days ago, fever is not high and no chills, at this time the patient does not have a fever.

The patient had no complaints of chest pain, night sweats, runny nose, olfactory disturbances, and taste disturbances. The patient also had no complaints of urinating (BAK) and defecating (BAB). The patient has a history of swallowing teeth and entering the airway 9 months ago. There is no history of contact with COVID- patient had no history of pulmonary tuberculosis, hypertension, diabetes mellitus, or malignancy. The patient's family history did not have a history of pulmonary tuberculosis, hypertension, diabetes mellitus, or malignancy.

The patient is a daily laborer and has a history of smoking 12 cigarettes per day for 20 years and has stopped 8 months ago with a smoking status with a moderate Brigman index. The patient lives with 8 family members and there are no respiratory complaints and fever in the family members.

General physical examination showed moderate pain, compos mentis consciousness, pulse 92 times/minute, blood pressure 130/90 $\mathrm{mmHg}$, respiratory rate 26 times/minute, body temperature $36^{\circ} \mathrm{C}$. On pulmonary examination, on inspection found left chest asymmetry flatter than the right chest in a static state, and the movement of the left chest lags behind the right chest in a dynamic state. On palpation, the left fremitus was weaker than the right fremitus. The percussion was not performed because the patient coughed up blood. An auscultation examination was not performed. On examination of the extremities, there was no edema in both legs.

Investigations were carried out by chest x-ray, noncontrast CT scan, and blood clinical chemistry examination. A chest x-ray (July 19th, 2021) showed signs of bronchiectasis and atelectasis. 19 patients, no history of gathering in crowds. The

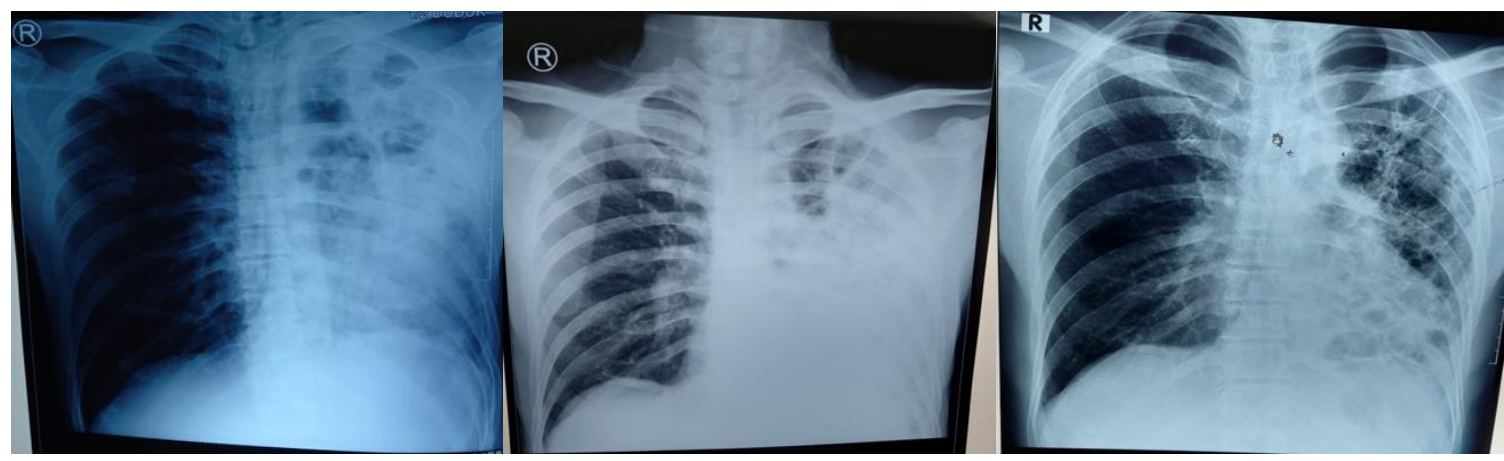

a)

b)

c)

Figure 1. a) Chest x-ray dated July 19th, 2021, at Dr. M Djamil General Hospital b) Chest x-ray on October 24th, 2020, at Dr. M Djamil General Hospital c) Chest x-ray on November $5^{\text {th }}, 2020$, at Dr. M Djamil General Hospital 


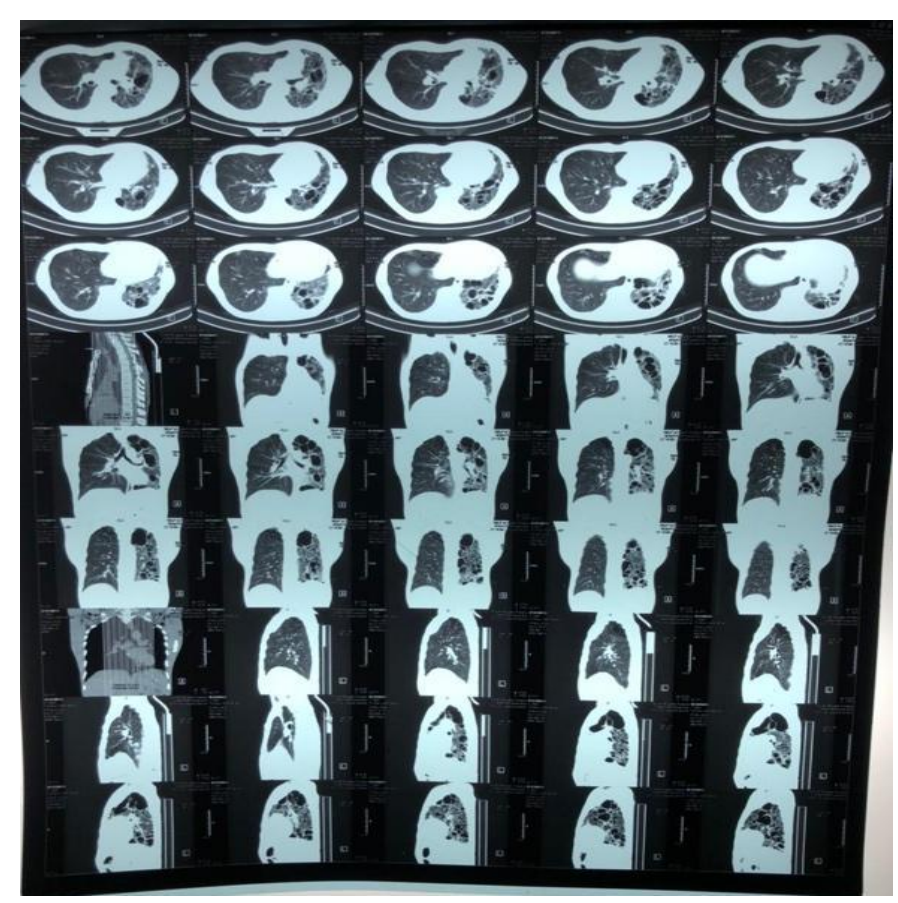

Figure 2. Thoracic CT Scan on $17^{\text {th }}$ November, 2020

Laboratory results on $19^{\text {th }}$ July, 2021:

$\begin{array}{llll}\text { HB } & : 10.0 \mathrm{~d} / \mathrm{dL} & \text { Total protein } \\ \text { Leukocytes } & : & 32.070 / \mathrm{mm}^{3} & \text { Albumin } \\ \text { Platelet } & : & 548.000 / \mathrm{mm}^{3} & \text { Globulin } \\ \text { Diff count } & : & \text { SGOT } \\ \text { PT } / \text { APTT } & : 11 / 88 / 6 / 5 & \text { SGPT } \\ \text { D-dimer } & : 3410 \mathrm{ng} / \mathrm{mL} & \text { Urea } \\ \mathrm{Na} / \mathrm{K} / \mathrm{Cl} & : & 132 / 3.8 / 100 \mathrm{mmol} / \mathrm{L} & \text { Creatinine }\end{array}$

Blood gas analysis:

$\begin{array}{llll}\mathrm{PH} & : 7,392 & \mathrm{HCO} 3^{-} & : 21.4 \\ \mathrm{PCO} 2 & : 34.9 & \mathrm{BE} & :-3.7 \\ \mathrm{PO} 2 & : 87.8 & \mathrm{SO} 2 & : 94.4\end{array}$

This patient was diagnosed with suspected COVID19, hemaptoe causes by infected bronchiectasis, multiple left bullae, suspected pulmonary TB. Therapy for this patient includes treatment in the yellow zone room, oxygen therapy using NRM 15 liters per minute, IVFD $\mathrm{NaCl}$ 0.9\% 12 hours/kolf, injection of Ampicillin Sulbactam 3x3gr, Levofloxacin infusion 1x 750mg, Nacetyl cysteine $2 \times 200 \mathrm{mg}$, Acid injection tranexamate $3 \times 500 \mathrm{mg}$, Injection of Vitamin K 3x1 tablet, Vitamin C $2 \times 250 \mathrm{mg}$ orally and Zinc $2 x 20 \mathrm{mg}$ orally. The examination plan is in the form of PCR swabs, sputum culture checks, BTA I, II checks, and Gen Xpert checks.

\section{Follow-up days 1-3 $\left(20^{\text {th }}-22^{\text {nd }}\right.$ July 2021)}

The patient complained of reduced shortness of breath, reduced cough with phlegm, no coughing up blood (1 day), and no fever. On examination, vital signs were found to be within normal limits with a respiratory rate of $22 x /$ minute and a saturation of $98 \%$ with a nasal cannula of 3 liters per minute. On auscultation on physical examination of the lungs found bronchovesicular breath sounds, crackles in both lung fields, and no wheezing. The PCR swab results were negative.

The patient's diagnosis was discarded COVID-19, hemaptoe couses by infected bronchiectasis, multiple 
left bullae, suspected pulmonary TB with continued therapy and the patient was transferred to the green zone. The plan is still waiting for the results of the sputum culture, BTA I, II and Gen Xpert.

\section{Follow-up day 4 (July 23th, 2021)}

The patient complained of reduced shortness of breath, reduced cough with phlegm, no coughing up blood, and no fever. On examination, vital signs were found within normal limits. On auscultation on physical examination of the lungs found bronchovesicular breath sounds, crackles in both lung fields, and no wheezing. On laboratory examination, it was found:

$\begin{array}{ll}\text { HB } & : 11.0 \mathrm{~d} / \mathrm{dL} \\ \text { Leukocytes } & : 10,080 / \mathrm{mm}^{3} \\ \text { Platelets } & : 426,000 / \mathrm{mm}^{3} \\ \text { HT } & : 31 \%\end{array}$

The results of BTA I, II on July 22 ${ }^{\text {nd }}$, 2021, were negative and the results of the X-pert gene were found MTB detected high, rifampin resistance not detected.

The patient's diagnosis was hemoptoe couses by infected bronchiectasis, multiple left bullae, and new cases of pulmonary tuberculosis confirmed bacteriologically. Therapy for the patient, the previous therapy was continued and starting on July 24th, 2021, the patient started taking category 1 anti-tuberculosis drugs (OAT) with rifampin 1x450mg, INH 1x300mg, pyrazinamide $1 \times 1250 \mathrm{mg}$, ethambutol 1x1000mg, and vitamin B6 1x10mg.

\section{Follow-up day 5-7 (July 24th-26th, 2021)}

The patient complained of shortness of breath that was no longer present, coughing up phlegm was reduced, coughing up blood was absent, and there was no fever. On examination, vital signs were found within normal limits. On auscultation examination on physical examination of the lungs found bronchovesicular rhonchi breath sounds were minimal in both lung fields and no wheezing.

The patient's diagnosis was hemaptoe couses by infected bronchiectasis, multiple bullae, pulmonary tuberculosis, a new case of bacteriologically confirmed in the treatment of OAT category 1 intensive phase on day 3. On the 7 th day of treatment the patient was allowed outpatient and planned for control to the pulmonary polyclinic.

\section{Discussion}

A 42-year-old male patient has been treated with complaints of coughing up blood since 1 day ago, coughing up yellowish phlegm that increased 1 week ago, shortness of breath 1 day ago, shortness of breath not shrinking. The patient complained of fever 3 days ago and no complaints of night sweats. The patient had a history of swallowing foreign bodies (dentures) 9 months ago. The patient was diagnosed with hemoptoe couses by infected bronchiectasis, multiple left bullae with pulmonary tuberculosis, a new case was confirmed bacteriologically from the history, physical examination, and investigations.

In patients with bronchiectasis, bronchiectasis is a chronic inflammatory disease of the airways with clinical characteristics and symptoms of chronic cough, increased sputum production and bronchial infection, as well as abnormal radiological features with permanent bronchodilation or dilation caused by weakening or damage to the muscle and elastic components of the bronchial tree. chest wall. The primary clinical manifestation of bronchiectasis is the occurrence of recurrent, chronic, or refractory infections, with sequelae that occur are coughing up blood, chronic airway obstruction, impaired clearance of secretions (marked by a very severe cough), and progressive breathing disturbances. 1,2,3,4,5

In the United States, from 2000 to 2007 the prevalence of bronchiectasis was reported to have increased. Seitz et al reported that the prevalence of bronchiectasis increased by $8.74 \%$ every year and occurred at the age of $80-84$ years. The prevalence of bronchiectasis is more common in women and Asian races. In the UK, prevalence increased year on year between 2004 and 2013, with increases in almost all age groups, but with the greatest increase in women over 70 where it increased from 21.24 per 100,000 person-years in 2004 to 35.17 per 100,000. people in 2013. Whereas in 2013, and men from 18.2 per 
100,000 person-years in 2004 to 26.92 per 100,000 person-years in 2013. Decreased FEV1 rates, advanced dyspnea symptom scores, positive Pseudomonas culture results, index Low basal metabolism, male, advanced age, and COPD have been identified as risk factors for mortality. ${ }^{3,4,5,16}$

Bronchiectasis is mostly caused by tuberculosis and will interfere with the patient's quality of life. According to the report on the control of pulmonary TB (tuberculosis) issued by the WHO in 2012, Indonesia is the fourth largest country in the world that has TB sufferers after India, China, and South Africa. Gothi et al in 2007 found out of 268 patients in tertiary health centers in India, 13\% of them had bronchiectasis, and $78 \%$ of them were post-tuberculosis patients. 15

Morphologically, bronchiectasis can be divided into 3: $6,7,18$ cylindrical or tubular bronchiectasis, characterized by airway dilatation. Cylindrical bronchiectasis shows a diffuse pattern of mucosal edema, with bronchi that are dilated but have straight and regular lines and have well-defined ends. The typical feature on HRCT for cylindrical bronchiectasis is a timeline of parallel trajectories. Sometimes a ringsignet appearance is seen consisting of a horizontal section of dilated bronchi with adjacent arteries.

Varicose bronchiectasis (the picture is similar to varicose veins), is characterized by a focal constrictive area accompanied by airway dilatation as a result of a defect in the bronchial wall or varicose bronchiectasis showing an irregular pattern of bronchial lumen characterized by alternating areas of dilatation and constriction. Often accompanied by post-obstructive pneumonitis and extensive parenchymal damage.

Cystic or saccular bronchiectasis is characterized by progressive dilatation of the airways ending in large cysts, saccule, or grape-like clusters. This appearance at first glance always looks like the appearance of emphysema, it's just that in emphysema the cystic appearance is usually very thin-walled and without the involvement of the proximal airways. This bronchiectasis is the most severe bronchiectasis.

\section{Pathogenesis}

The pathogenesis of bronchiectasis can be explained by the Cole's vicious circle model also called Cole's vicious circle. Cole explained that in patients with a predisposition to have a severe inflammatory response to lung infection or tissue injury. Inflammation that occurs is responsible for damage to airway structures. Airway inflammation is dominated by neutrophil chemoattractants, especially interleukin-8 (CXCL-8) and leukotrienes B4. The inflammatory response involving neutrophils, lymphocytes, and macrophages, as well as inflammatory products released by microorganisms and the body's defenses (proteases, collagenases, and free radicals), will make the bronchial walls weak because they lose their muscular and elastic elements. Neutrophil elastase (NE) decreases the rate of mucociliary clearance and increases mucus secretion, resulting in mucus stasis. Mucus stasis and decreased phagocytic ability of neutrophils will lead to bacterial colonization of the sinobronchial tree. ${ }^{8}$

Decreased ability of opsono-phagocytosis occurs in several levels, namely the breakdown of opsonins through the outer surface of bacteria and the breakdown of neutrophil receptors. The release of alpha-defensins from neutrophil granules also suppresses phagocytosis. Another mechanism of immune dysfunction that has an effect is a decrease in the clearance of apoptosis and $\mathrm{T}$ cell infiltration. The result of the above process is the formation of bacterial colonization which causes chronic inflammation and becomes a vicious cycle that becomes progressive again so that it further damages the lungs. ${ }^{8}$ 


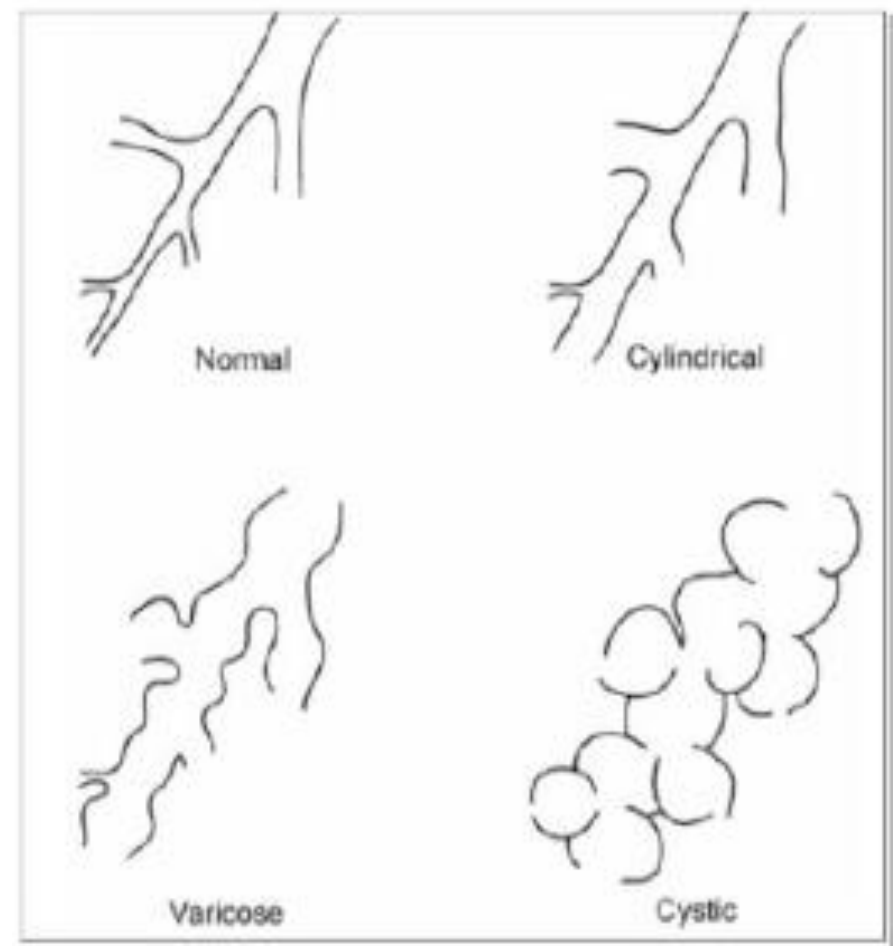

Figure 3. Types of bronchiectasis

\section{Neutrophil Inflammation (Proteases)}

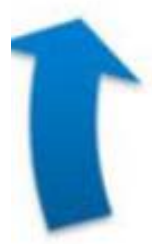

\section{Bacterial Colonization}

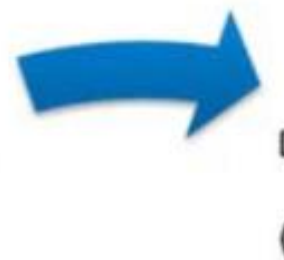

\section{Airway \\ Destruction and \\ Distortion \\ (Bronchiectasis)}

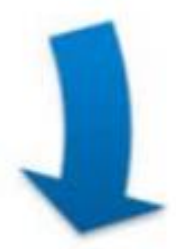

Abnormal

Mucus

Clearance

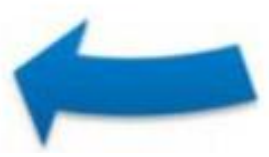

Figure 4. The hypothesis of the vicious circle of bronchiectasis.

The cause of bronchiectasis $50-80 \%$ is still idiopathic, a British study in 2000 of 150 patients found $53 \%$ idiopathic causes. The causes of bronchiectasis can be seen in table 1.5,7 


\begin{tabular}{|l|}
\hline Table 1. Conditions related to bronchiectasis 7 \\
\hline Post-infectious conditions \\
\hline Bacteria (pseudomonas, Hemophilus) \\
\hline Mycobacterium tuberculosis \\
\hline Aspergillus sp \\
\hline Virus (adenovirus, measles virus, influenza virus, human immunodeficiency virus) \\
\hline Congenital conditions \\
\hline Primary ciliary dyskinesia \\
\hline Alpha1-antitrypsin deficiency \\
\hline Cystic fibrosis \\
\hline Tracheobronchomegaly (Mounier-Kuhn syndrome) \\
\hline Cartilage deficiency (William-Campbell syndrome) \\
\hline Pulmonary sequestration \\
\hline Marfan's syndrome \\
\hline Immunodeficiency \\
\hline Primary \\
\hline hypogammaglobulinemia \\
\hline Secondary \\
\hline Caused by cancer modulation (chronic lymphatic leukemia), chemotherapy, or after \\
transplantation of the immune system) \\
\hline Sequelae of inhalation of toxic gasses or aspiration \\
\hline Chlorine \\
\hline Overdose (heroin) \\
\hline Foreign body \\
\hline Rheumatic conditions \\
\hline Rheumatoid arthritis \\
\hline Systemic lupus erythematosus \\
\hline Sjogren's syndrome \\
\hline Relapsing polychondritis \\
\hline Other causes \\
\hline Inflammatory bowel disease (chronic ulcerative colitis or Crohn's disease) \\
\hline Young's syndrome (seconda) ry ciliary dyskinesia) \\
\hline Yellow nail syndrome (yellow nails and lymphedema) \\
\hline
\end{tabular}

In patients, bronchiectasis is caused by aspiration of foreign bodies which can cause airway obstruction which is characterized by atelectasis so that there is no incoming airflow so that the intrapleural pressure is more negative than atmospheric pressure causes bronchial dilatation. In the dilated bronchi, there is a decrease in the clearance of the mucosilia, resulting in a collection of secretions or mucus making it easy for infection to occur.

\section{Clinical manifestations}

The clinical overview of bronchiectasis varies widely, some patients have no symptoms at all or symptoms are only felt during exacerbations, and some patients experience symptoms every day. Bronchiectasis can be found in patients with chronic productive cough with profuse mucopurulent sputum (usually $200 \mathrm{ml}$ in 24 hours) or recurrent respiratory tract infections. However, sputum can also vary from mucoid, mucopurulent, thick, and tough. The appearance of 3 layers of sputum which includes a foamy upper layer, a middle layer of mucus, and a purulent lower layer is pathognomonic, but not always present. However, dry cough without phlegm can also be a symptom of bronchiectasis. Complaints are usually chronic progressive that is getting worse from year to year. Other complaints are shortness of breath, coughing up blood / hemoptoe, and non-specific symptoms such as fatigue and weight loss. Pleuritic chest pain is sometimes present. The physical findings on physical examination of patients with bronchiectasis are nonspecific, rhonchi and wheezing on lung auscultation are often found in the lower lobes and clubbing fingers on the fingers. ${ }^{8}$

Exacerbation of bronchiectasis occurs when 4 or more of the following symptoms are present: cough with increased phlegm, increased shortness of breath, increased body temperature $>38^{\circ} \mathrm{C}$, increased 
lung function, and signs of acute infection are present.

\begin{tabular}{|l|}
\hline Table 2. Symptoms of Bronchiectasis with Acute Exacerbation 5 \\
\hline Changes in sputum production \\
\hline Shortness of breath increases \\
\hline Cough increases \\
\hline Fever (body temperature $>38.0^{\circ} \mathrm{C}$ \\
\hline Malaise fatigue, lethargy, or decreased tolerance for physical activity \\
\hline Decreased lung function Pulmonary physiology \\
\hline changes that are consistent with the infiltration process Lung \\
\hline changes in breath sounds \\
\hline
\end{tabular}

Laboratory investigations in bronchiectasis are nonspecific but are important for individual monitoring. Hemoglobin levels may be low due to anemia in chronic disease, polycythemia may also occur as a result of chronic hypoxia. Elevated white blood cells indicate acute infection. ${ }^{11}$

The diagnosis of bronchiectasis can be confirmed by radiological examination, with the standard using highresolution computed tomography (HRCT).On chest Xray bronchiectasis can be seen with tram track images, the density of parallel lines, the density in the form of ring shadow can be vaguely measured $5 \mathrm{~mm}$ until formation cyst clear the appearance of tubular opacities that form branches according to the shape of the bronchial branches can be seen as a result of the bronchi being filled with mucous fluid. ${ }^{11,12}$

Management of bronchiectasis includes identification of acute exacerbations and use of antibiotics, control of microbial growth, treatment of the underlying condition, reduction of the excessive inflammatory response, improvement of bronchial hygiene, control of bronchial bleeding, surgical therapy to remove the affected lung segment or lobe. severe damage that can be a source of infection or bleeding. ${ }^{11}$

\section{Antibiotics}

Antibiotics have a crucial role in the management of bronchiectasis, antibiotics can inhibit the vicious cycle of infection, inflammation, and airway epithelial damage. The use of antibiotics is needed as therapy during exacerbations or as a long-term therapy. Early use of antibiotics in exacerbations can limit the vicious circle. The duration of antibiotic therapy is still a matter of debate, however, the British Thoracic Society guidelines for non-CF Bronchiectasis 2010 stated that in exacerbation conditions, antibiotics were given for 14 days. According to British Thoracic Society guidelines for non-CF Bronchiectasis, if there is no bacteriological data, the first-line antibiotic that can be used is amoxicillin $500 \mathrm{mg}$ three times a day or clarithromycin $500 \mathrm{mg}$ twice a day (for penicillin allergy sufferers) for 14 days. High-dose regimens (e.g. amoxicillin 1 gram three times daily, or amoxicillin 3 grams twice daily) may be required in patients with severe bronchiectasis who have chronically colonized Haemophilus influenza. Ciprofloxacin can be given to patients with Pseudomonas aeruginosa, which should be used with caution in the elderly. 6,13,14 
Table 3. Antibiotics recommended for acute exacerbation of bronchiectasis. ${ }^{14}$

\begin{tabular}{|c|c|c|c|c|}
\hline Organism & Recommended first-line treatment & Length of treatment & Recommended second-line treatment & Length of treatment \\
\hline Streptococcus pneumoniae & Amoxicillin $500 \mathrm{mg}$ tds & 14 days & Clarithromycin $500 \mathrm{mg}$ bd & 14 days \\
\hline $\begin{array}{l}\text { Haemophilus influenzae ( } \beta \text {-lactamase } \\
\text { negative) }\end{array}$ & $\begin{array}{l}\text { Amoxicilin } 500 \mathrm{mg} \text { tds } \\
\text { Amoxicilin } 1 \mathrm{~g} \mathrm{tds} \\
\text { Amoxicilin } 3 \mathrm{~g} \text { bd }\end{array}$ & $\begin{array}{l}14 \text { days } \\
14 \text { days } \\
14 \text { days }\end{array}$ & $\begin{array}{l}\text { Clarithromycin } 500 \mathrm{mg} \text { bd or ciprofloxacin } \\
500 \mathrm{mg} \text { bd or ceftriaxone } 2 \mathrm{~g} \text { od (IV) }\end{array}$ & 14 days \\
\hline $\begin{array}{l}\text { Haemophilus influenzae ( } \beta \text {-lactamase } \\
\text { positive) }\end{array}$ & Co-amoxiclav $625 \mathrm{mg}$ tds & 14 days & $\begin{array}{l}\text { Clarithromycin } 500 \mathrm{mg} \text { bd or ciprofloxacin } \\
500 \mathrm{mg} \text { bd or ceftriaxone } 2 \mathrm{~g} \text { od (IV) }\end{array}$ & 14 days \\
\hline Moraxella catarrhalis & Co-amoxiclav $625 \mathrm{mg}$ tds & 14 days & Ciprofloxacin $500 \mathrm{mg}$ bd & 14 days \\
\hline Staphylococcus aureus (MSSA) & Flucloxacillin $500 \mathrm{mg}$ qds & 14 days & Clarithromycin $500 \mathrm{mg}$ bd & 14 days \\
\hline \multirow[t]{3}{*}{$\begin{array}{l}\text { Staphylococcus aureus (MRSA): oral } \\
\text { preparations }\end{array}$} & $\begin{array}{l}<50 \mathrm{~kg}: \text { Rifampicin } 450 \mathrm{mg} \text { od + } \\
\text { trimethoprim } 200 \mathrm{mg} \text { bd }\end{array}$ & 14 days & $\begin{array}{l}<50 \mathrm{~kg}: \text { Rifampicin } 450 \mathrm{mg} \text { od + } \\
\text { doxycycline } 200 \mathrm{mg} \text { od }\end{array}$ & 14 days \\
\hline & $\begin{array}{l}>50 \mathrm{~kg}: \text { Rifampicin } 600 \mathrm{mg}+ \\
\text { trimethoprim } 200 \mathrm{mg} \text { bd }\end{array}$ & & $\begin{array}{l}>50 \mathrm{~kg} \text { : Rifampicin } 600 \mathrm{mg}+ \\
\text { doxycycline } 200 \mathrm{mg} \text { od }\end{array}$ & 14 days \\
\hline & & & Third-line: Linezolid $600 \mathrm{mg}$ bd & 14 days \\
\hline $\begin{array}{l}\text { Staphylococcus aureus (MRSA): } \\
\text { intravenous preparations }\end{array}$ & $\begin{array}{l}\text { Vancomycin } 1 \mathrm{~g} \mathrm{bd*} \text { (monitor serum } \\
\text { levels and adjust dose accordingly) or } \\
\text { teicoplanin } 400 \mathrm{mg} \text { od }\end{array}$ & 14 days & Linezolid $600 \mathrm{mg}$ bd & 14 days \\
\hline Coliforms (eg, Klebsiella, enterobacter) & Oral ciprofloxacin 500 mg bd & 14 days & Intravenous ceftriaxone $2 \mathrm{~g}$ od & 14 days \\
\hline \multirow[t]{2}{*}{ Pseudomonas aeruginosa } & $\begin{array}{l}\text { Oral ciprofloxacin } 500 \mathrm{mg} \text { bd }(750 \mathrm{mg} \text { bd } \\
\text { in more severe infections) }\end{array}$ & 14 days & $\begin{array}{l}\text { Monotherapy: Intravenous ceftazidime } 2 \mathrm{~g} \\
\text { tds or tazocin } 4.5 \mathrm{~g} \text { tds or aztreonam } 2 \mathrm{~g} \\
\text { tds or meropenem } 2 \mathrm{~g} \text { tds }\end{array}$ & 14 days \\
\hline & & & $\begin{array}{l}\text { Combination therapy: The above can be } \\
\text { combined with gentamicin or tobramycin } \\
\text { or colistin } 2 \mathrm{MU} \text { tds }(<60 \mathrm{~kg}, 50000 \text { - } \\
75000 \text { units } / \mathrm{kg} \text { daily in } 3 \text { divided doses) }\end{array}$ & 14 days \\
\hline
\end{tabular}

The patient, in this case, had infected bronchiectasis or it could also be called exacerbation of bronchiectasis because the patient had symptoms of increased shortness of breath, complaints of increased cough and changes in sputum production, presence of fever, Radiological signs of infection, and laboratory examination found an increase in leukocytes. In this condition, the patient received antibiotic therapy in the form of injection of Ampicillin Sulbactam 3x3gr and levofloxacin infusion $1 \times 750 \mathrm{mg}$.

The patient also found multiple bullae on a chest CT scan. Pulmonary bullae are air-filled spaces in the lung parenchyma that result from the destruction of alveolar tissue. Bullae arise as a result of the destruction, dilatation, and union of air spaces in the most distal airways to the terminal bronchioles. Bulla is a complication of emphysema where emphysema causes loss of elasticity of the alveolar walls. On the way, the walls of the alveoli will stretch to be large but less efficient in the process of exchanging oxygen and carbon dioxide during the respiratory process. Difficulty in the expiration process will lead to the trapping of air in the lungs, which is known as hyperinflation. Emphysema is characterized by abnormal and permanent widening of the air spaces distal to the terminal bronchioles. The underlying disorder is diffuse destruction of the alveolar walls without marked fibrosis, which is chronically progressive and results in permanent disability. Parenchymal structural abnormalities begin with chronic inflammation which will destroy airway wall elastic tissue. Emphysema that occurs in patients is compensatory emphysema which is a disorder in the form of the hyperinflation of certain parts of the lung that occurs due to atelectasis. 19,20

The condition of bronchiectasis in patients causes the presence of epithelium and cilia to disappear so that mucociliary clearance is reduced which results in the accumulation of secretions so that infection is easy, one of which is pulmonary tuberculosis infection. Due to the presence of pulmonary tuberculosis infection, the patient was given anti-tuberculosis drugs. 


\section{Conclusion}

Bronchiectasis is a disease characterized by pathological and chronic dilatation of the bronchi. The dilation causes reduced airflow to and from the lungs. For this reason, bronchiectasis is classified as chronic obstructive pulmonary disease, which manifests as inflammation of the airways and collapses easily, causing airflow obstruction and causing shortness of breath, impaired mucus clearance usually accompanied by coughing, and sometimes hemoptysis.

In patients, bronchiectasis is caused by aspiration of foreign bodies which can cause airway obstruction which is characterized by atelectasis so that there is no incoming airflow so that the intrapleural pressure is more negative than atmospheric pressure causing the bronchi to dilate. In the dilated bronchi, there is a decrease in the clearance of the mucosilia, resulting in a collection of secretions or mucus making it easy for infection to occur.

In patients found multiple bullae which are complications of emphysema and in patients experiencing or there is compensatory emphysema in which the abnormality is in the form of the hyperinflation of certain parts of the lung that occurs due to atelectasis. The condition of bronchiectasis and multiple bullae makes the patient susceptible to infection, which in this case was found to have pulmonary tuberculosis infection.

Management of bronchiectasis includes identification of acute exacerbations and the use of antibiotics, controlling microbial growth, treatment of the underlying condition, and reducing the excessive inflammatory response.

\section{References}

1. Chalmers JD. Bronchiectasis and COPD overlap: A case of mistaken identity. American College of Chest Physician [Internet]. 2017. Available from http://dx.doi.org/10.1016/j.chest. 2016; 12: 02

2. Eva P, Pieter CG, Melissa JM, Stefano A, Sara EM, Michael RL. European respiratory society guidelines for the management of adult bronchiectasis. Eur Respir J. 2017; 50: 1700629

3. James DC, Stefano A, Francesco B. Management of bronchiectasis in adults. Eur Respir J. 2015; 45: 1446-62

4. King PT. The pathophysiology of bronchiectasis. Internat J COPD. 2009; 4: 411

5. O'Donnell AE. Bronchiectasis. Chest 2008; 134(4): 815-23

6. Pamela J, McShane I, Edward T, Naureckas I, Gregory T, Mary E. Non-Cystic Fibrosis Bronchiectasis. American Journal of Respiratory And Critical Care Medicine 2013; 188: 647-656

7. Neves PC, Guerra M, Ponce P, Miranda J, Vouga L. State-of-the-art - Pulmonary Noncystic fibrosis bronchiectasis. Interactive CardioVascular and Thoracic Surgery 2011; 13: 619-625

8. Nur prasetyo nugroho. Bronchiectasis. CDK Supplementary Edition-2, Vol. 45. 2018: 68-74

9. Barker AF. Bronchiectasis. the New England Journal of Medicine 2002; 346: 1383-1393

10. Elborn JS, Drain M. Assessment and Investigation of Adults with Bronchiectasis. Eur Respira Mon 2011; 2: 52-35

11. Rademacher J, Welte T. Bronchiectasisdiagnosis and treatment. Deutsches Orzteblatt International | Dtsch Arztebl Int 2011; 108(48): 809-1

12. Perea OT, Screaton NJ. Radiological feature of bronchiectasis. european respiratory monograph: Bronchiectasis.2011;2:44-65

13. Haworth CS. Antibiotic treatment in adults with bronchiectasis. European Respiratory Monograph: Bronchiectasis. 2011; 2: 211-222

14. Pasteur MC, Bilton D, Hill A T. British thoracic society guidelines for non-CFbronchiectasis. 2010

15. Sheila vinesa. Distribution Pattern of Bronchiectasis in the Pulmonary Polyclinic, RSU Dr. Soedarso Pontianak Period January 2010 - December 2011. Medical Education 
Study Program, Faculty of Medicine and Health Sciences, Tanjungpura University. 2013: 1-19

16. Quint JK, ME Changes in the incidence, prevalence and mortality of bronchiectasis in the UK from 2004 to 2013: a population-based cohort study. Eur Respir J. 2016; 47; 186-193.

17. Arimbi. Bronchiectasis. Department of Internal Medicine UWK Surabaya. 2014: 1-22

18. Andika Pradana. Diagnosis and Management of Bronchiectasis. Faculty of Medicine, University of North Sumatra. Medan. 2019: 134

19. Fauzie Maulana. Active Pulmonary Tuberculosis + Giant Bullae + TB Meningitis + Inflammatory Anemia. Tasikmalaya District Hospital Singaparna Medical Citrautama (SMC). 2016; 1-72

20. Gian, Puja, Fadilah, Muh. Rakib, Joestiatho. Multiple Giant Bulls and Pleural Effusion. Department of Radiology, Faculty of Medicine, Hasanuddin University, Makassar. 2019; 1-34 